\title{
Early diagnosis of severe combined immunodeficiency syndrome
}

\author{
R A Hague, S Rassam, G Morgan A J Cant
}

\begin{abstract}
Infants with severe combined immunodeficiency syndrome (SCIDS) have a greatly improved prognosis if diagnosed and treated before they develop overwhelming infection. Clinical and laboratory data on 45 patients with SCIDS were retrospectively reviewed to assess the value of absolute lymphocyte counts in making an early diagnosis. Ninety infants matched for age, sex, and presenting symptoms were used as controls. Thirteen
\end{abstract} $(29 \%)$ infants with SCIDS were diagnosed at birth as previous siblings had been affected; 32 (71\%) were diagnosed after the development of symptoms. Eighteen $(56 \%)$ of these remained undiagnosed until after 6 months of age. The first symptoms occurred at a median of 5 weeks (range 1 day to 8 months) and the first admission to hospital was at 4 months (range 1 week to 16 months). Symptoms included respiratory infection $(91 \%)$, vomiting and diarrhoea $(81 \%)$, failure to thrive $(88 \%)$, candidiasis $(50 \%)$, and skin lesions $(28 \%)$. The mean lymphocyte count was $1.71 \times 10^{9} / 1$ compared with $7 \cdot 2 \times 10^{9} / 1$ in controls. Excluding one child with Omenn's syndrome (lymphocyte count $23.3 \times 10^{9} / 1$ ), all symptomatic infants with SCIDS had lymphocyte counts less than $2.8 \times 10^{9} /$ at presentation. The median delay between the first abnormal lymphocyte count and diagnosis was seven weeks (range one day to 13 months). Twenty eight $(88 \%)$ of 32 infants would have been diagnosed before 6 months of age if investigated after the first low lymphocyte count. These data indicate that low lymphocyte counts are predictive of SCIDS. Paediatricians are urged to pay attention to the absolute lymphocyte counts in all infants in whom a full blood count is performed. Those with lymphocyte counts persistently less than $2.8 \times 10^{9} \|$ should be investigated for SCIDS.

(Arch Dis Child 1994; 70: 260-263)

Severe combined immunodeficiency syndrome (SCIDS) is a heterogeneous group of inherited disorders characterised by the failure of cellular and humoral immunity. Children present with recurrent or persistent infections and without treatment die within the first year of life from overwhelming infection. ${ }^{1}$ The prognosis of children with SCIDS has been transformed by bone marrow transplantation and data from a European collaborative study of affected infants (in which Newcastle upon Tyne and London are the participating centres in the UK) have shown $97 \%$ long term survival for recipients of HLA identical sibling marrow and $52 \%$ survival for recipients of HLA mismatched (haploidentical) marrow from a parent. ${ }^{2}$ The survival rate for infants transplanted after 6 months of age is only $45 \%$, however, compared with $70 \%$ in younger children. Although facilities for bone marrow transplantation for the treatment of SCIDS are available within the UK, many affected children without a family history are older than 6 months of age at referral, or are terminally ill with overwhelming infection, making transplantation a risky procedure.

The incidence of SCIDS is one in 66000 live births in most parts of the world, ${ }^{3-6}$ although it is higher in some populations. ${ }^{7}$ Thus in paediatric practice in the UK a case will be encountered only rarely. Early symptoms and signs can be non-specific and only after a number of infective episodes, or an infection of unusual severity, may immunodeficiency be suspected. A full blood count with differential white blood cell count is usually performed in infants with an infection severe enough to merit admission to hospital. Previous workers have reported conflicting data on the proportion of infants with SCIDS who are lymphopenic. ${ }^{8-10}$ We have therefore documented the presenting clinical features of such infants and studied the usefulness of their absolute lymphocyte count in alerting a paediatrician to the possibility of SCIDS at an early stage when immediate treatment would greatly improve the prognosis.

\section{Methods}

Patients with SCIDS seen in Newcastle upon Tyne, London, and Edinburgh were identified from hospital records. Clinical and laboratory data on each child were reviewed retrospectively and for those referred from elsewhere additional data about the initial presentation were sought from the referring hospital. Two control groups were identified among infants presenting to Newcastle General Hospital. The first group consisted of infants matched
Correspondence to: Dr A J Cant, Department of Paediatric Immunology, Newcastle General Hospita Westgate Road, Newcasth

Accepted 5 December 1993 


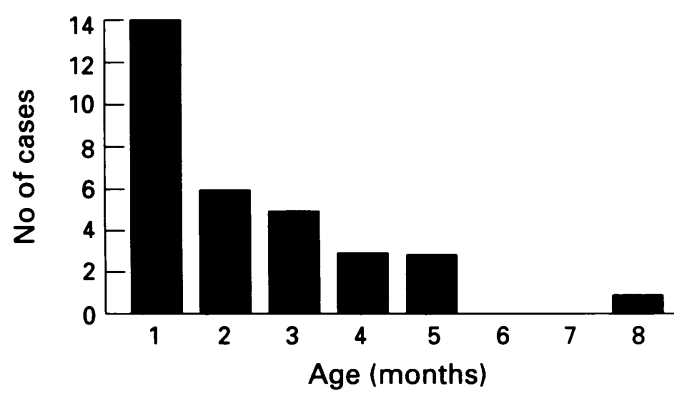

Figure 1 Age of development of first symptoms in index children.

for age and first presenting symptom (for example, chest infection, wheeze, diarrhoea, failure to thrive) with the infants with SCIDS presenting with infection. The second control group consisted of uninfected term infants undergoing blood counts either before an operation or for the investigation of jaundice, and was matched with the infants with SCIDS who were diagnosed at birth because of a family history of the syndrome.

White cell counts in index cases and controls were measured by an automated Coulter method and blood was also filmed for a differential white cell count. Statistical analysis of the two groups used Student's $t$ test.

\section{Results}

Forty five children with SCIDS were identified and each child was matched with two control children from the appropriate group (90 children). Thirteen (29\%) infants were diagnosed at or around the time of birth and were asymptomatic (all had a family history of a previously affected sibling). Thirty two $(71 \%)$ children with no family history of SCIDS were diagnosed once symptoms had developed. Of these only $14(44 \%)$ were diagnosed before the age of 6 months. As shown in fig 1, the median age for the develop-

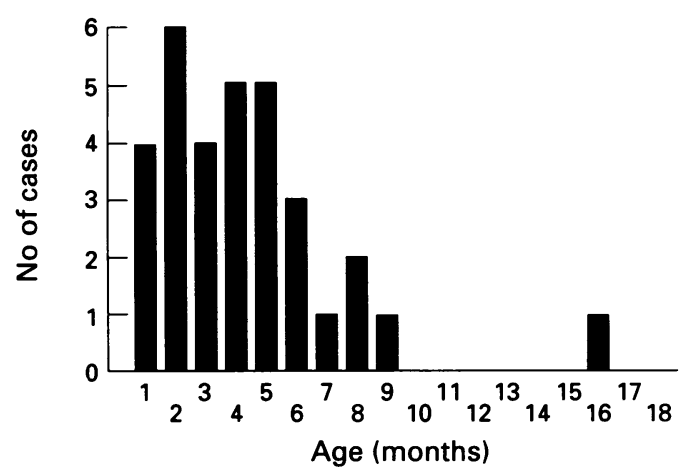

Figure 2 Age of first hospital admission for symptomatic index children.

Frequency and median (range) age of onset of commonly observed symptoms in index children

\begin{tabular}{lcc}
\hline & $\begin{array}{c}\text { No (\%) of } \\
\text { children }\end{array}$ & Median (range) age of onset \\
\hline Respiratory infection & $30(94)$ & 10 Weeks (1 day to 9 months) \\
Vomiting/diarrhoea & $26(81)$ & 4 Months (1 week to 14 months) \\
Candidal infection & $15(47)$ & 3 Months (2 weeks to 10 months) \\
Failure to thrive & $28(88)$ & 10 Weeks (1 to 11 months) \\
Skin sepsis & $9(28)$ & 3 Months (1 to 8 months) \\
\hline
\end{tabular}

ment of symptoms was 5 weeks, the earliest being at 1 day of age. Only one child, who first became unwell at 8 months, had been asymptomatic at 6 months of age.

The median age on first admission for symptomatic infants was 4 months (range 1 week to 16 months) (fig 2). Respiratory infection (cough and wheeze, or less commonly pneumonia), seen in 22 infants, was the most common presenting symptom. Nine presented with vomiting and diarrhoea, eight with candidal infection, six were failing to thrive, and two had skin sepsis. Six children had only one of these symptoms by the time they were first admitted to hospital, eight had two, 10 had three, eight had four, and one had all five (one was admitted for an unrelated cause). The diagnosis of SCIDS was not made until a median age of 7 months (range 4 weeks to 16 months). By the time all infants had at least two symptoms and most were failing to thrive. The age of onset of the commonly observed symptoms and their frequency among the group is shown in the table.

Twenty eight $(88 \%)$ of the 32 infants had a 'routine' blood count checked at the time of the first hospital admission, the count not being checked until later in the other four infants. The median age for the first blood count was 4 months (range 1 week to 11 months). The mean total white cell count in these infants was in the normal range at $8.29 \times 10^{9} / 1$ and did not differ significantly from the controls $\left(9 \cdot 25 \times 10^{9} / 1\right)$ : only five were leucopenic (white cell count $<4.0 \times 10^{9} / 1$ ) and seven had a white cell count greater than $11 \times 10^{9} /$. In 44 infants with SCIDS, excluding the one child with Omenn's syndrome (lymphocyte count $23.4 \times 10^{9} / 1$ ), the mean lymphocyte count was $1.72 \times 10^{9} / 1$ compared with $6.02 \times 10^{9} / 1$ in controls $(\mathrm{p}<0.001)$.

Figure 3 illustrates the distribution of lymphocyte counts in index and control children. All symptomatic infants except the one with Omenn's syndrome had lymphocyte counts less than $2 \cdot 8 \times 10^{9} / 1$ and their lymphopenia persisted on repeat sampling. Five control children also had lymphocyte counts $<2 \cdot 8 \times 10^{9} / 1$ on initial presentation, but in these the counts were normal on repeat testing. In the index children lymphocyte counts tended to decrease with time, despite the children being treated for their presenting infection. For the symptomatic children the false positive rate for SCIDS among children with a lymphocyte count $<2 \cdot 8 \times 10^{9} / 1$ was $8 \%$, with a positive predictive value of $86 \%$ and a negative predictive value of $100 \%$. For all the children the positive predictive value was $93 \%$ and the negative predictive value was $93 \%$.

Although the most rapid diagnosis after the first blood count was made the next day, the median delay between the first low lymphocyte count and diagnosis was seven weeks. One child was only diagnosed 13 months later. Only four children did not receive a blood count in the first six months of life, and so 28 could have been diagnosed before this time if investigated after the first abnormal lymphocyte count. 


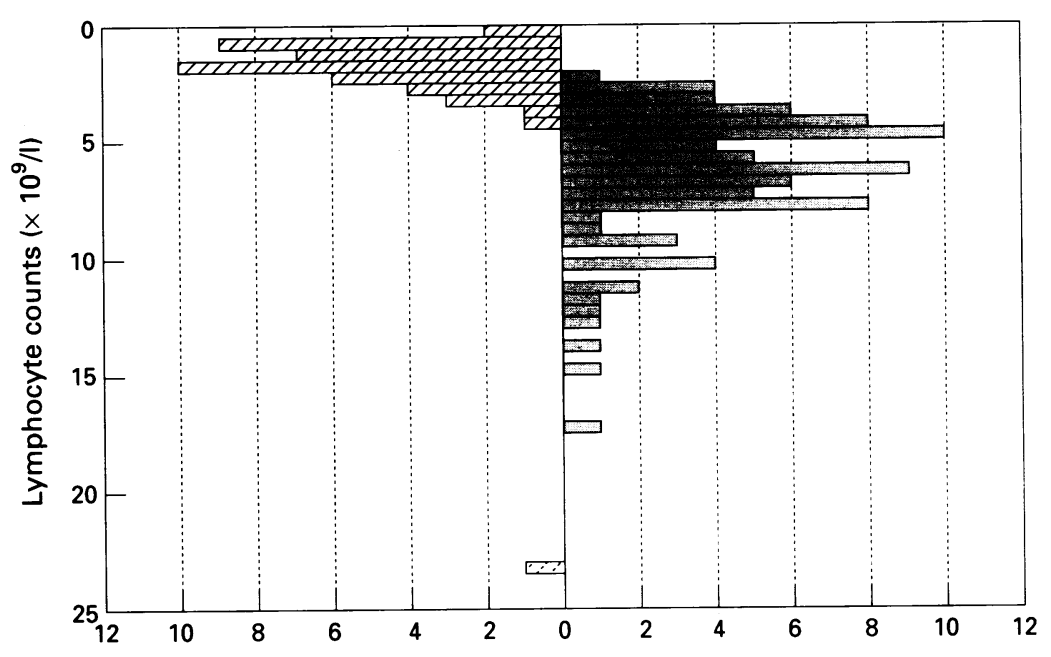

Figure 3 Histogram of lymphocyte counts from index and control infants in increments of $0.5 \times 10^{9} \pi$.

\begin{abstract}
Discussion
It has long been recognised that infants with SCIDS may be lymphopenic, but the proportion of infants reported to have subnormal lymphocyte counts has varied from $10-20 \%$ to $96 \%{ }^{8-10}$ The $95 \%$ reference range for lymphocyte counts in the first year of life varies from $2 \cdot 0-11 \cdot 0 \times 10^{9} / 1$ at birth to $4 \cdot 0-13 \cdot 5 \times 10^{9} / 1$ at 6 months to 1 year. ${ }^{11} \mathrm{We}$ chose a cut off point for lymphopenia of $2 \cdot 8 \times 10^{9} / 1$ as the value under which counts from all the symptomatic infants with SCIDS lay. Five asymptomatic infants with SCIDS had higher lymphocyte counts at birth, and this value will therefore be less discriminatory for infants in the first month of life. If a persistently low lymphocyte count is noted in a child free of infection, however, investigation is probably still justified. It should be emphasised that a normal lymphocyte count does not preclude the diagnosis of SCIDS, ${ }^{12} 13$ and occasionally even lymphocyte subsets can be normal, so that infants with higher counts
\end{abstract}

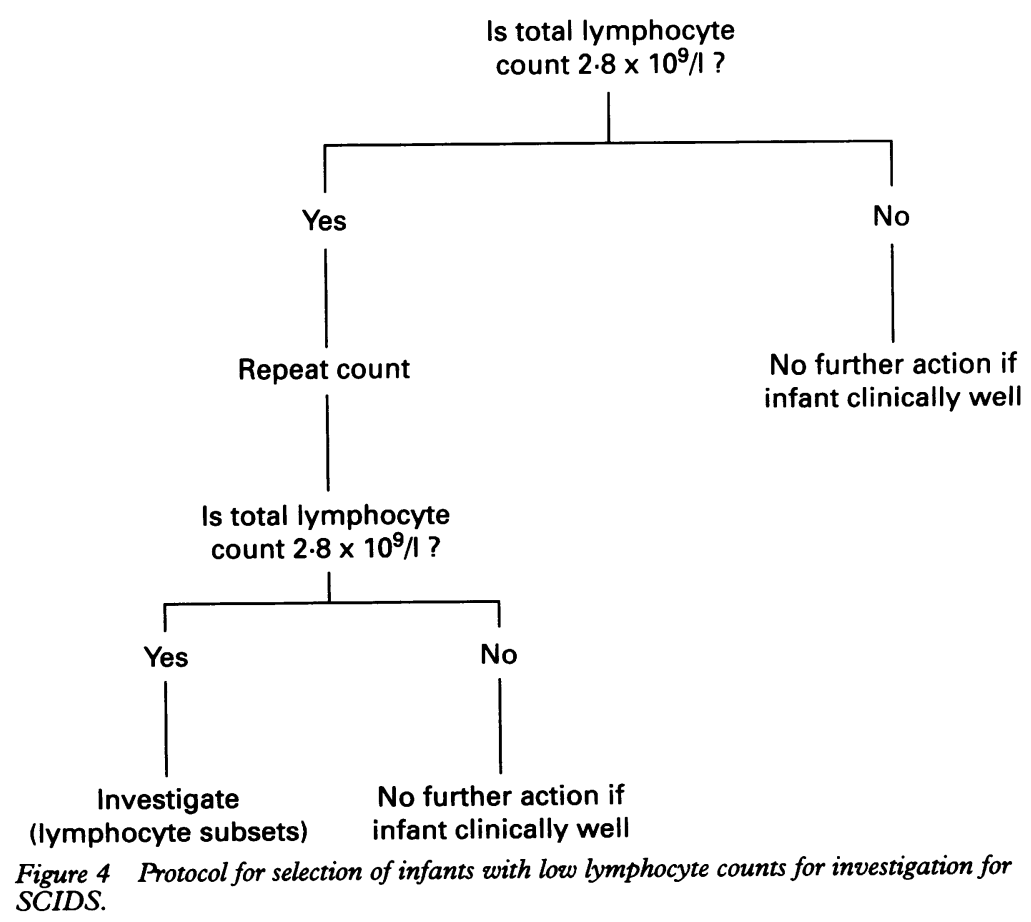

in whom there is a clinical suspicion of immunodeficiency should also be investigated.

As Gossage and Buckley point out, ${ }^{10}$ the lower limit of the $95 \%$ reference range for lymphocyte counts in infants is much higher than in older children or adults, in whom lymphopenia is defined as $<1.0 \times 10^{9} /$. $^{11}$ This has been overlooked by reviewers of SCIDS ${ }^{9}$ and by Hosking and Roberton when formulating a score for when to investigate a child for immunodeficiency. ${ }^{14}$ The insensitivity of this scoring system has already been shown by Lyall et al, ${ }^{15}$ in whose series this system did not identify two children with SCIDS, perhaps because the wrong criteria for lymphopenia were used. It is hardly surprising therefore that a lymphocyte count of between 1 and $2 \cdot 8 \times 10^{9} / 1$ should escape recognition when it is more usual to pay attention to the total white cell count and neutrophil count than to work out the absolute lymphocyte count from the differential percentages. Our data indicate that this calculation is of vital importance.

The pattern of symptoms and signs which we observed among infants with SCIDS is similar to those reported by other groups. ${ }^{2}$ 5-8 16 Although some features may be highly suggestive of SCIDS, such as the cutaneous manifestations in a child with maternofetal engraftment, ${ }^{17}$ most could also be seen in children with other immunodeficiencies including HIV infection, and also in normal children, particularly those from poorer socioeconomic backgrounds. ${ }^{18}$ The control data from our study shows that even during acute infections, many of which will be viral in origin, the mean lymphocyte count usually remains within the normal range. The control infants who were lymphopenic on initial blood count were easily distinguished from those with SCIDS as their lymphocyte count returned to normal within a few days.

On the basis of our findings we propose the algorithm outlined in fig 4 for the further investigation of children under 1 year of age presenting to hospital who have full blood counts checked and are found to be lymphopenic. Lymphocyte subset analysis should be performed on all those whose lymphopenia persists, as well as those in whom there is a clinical suspicion of immunodeficiency. Immunoglobulin is more often measured as a screening test, but in the early months of life is less useful and may be misleading because of the transplacental transfer of maternal IgG and physiologically low concentrations of IgA and IgM at this age.

Infants with SCIDS admitted to hospital before a diagnosis is made often acquire nosocomial infections such as respiratory syncytial virus and rotavirus while being nursed in an unprotected environment; these infections are often fatal. There is therefore considerable urgency in the recognition of the low lymphocyte count and further investigation, so that an affected child can be nursed in aseptic isolation and definitive treatments started as soon as possible. The additional cost of a repeat full blood count is cheap at about $£ 3.50$, and only a small number of infants should need 
lymphocyte subset analysis, which costs about $£ 75$. This is surely justified when compared with the enormous cost, both human and financial, of the unsuccessful treatment of an infant with SCIDS diagnosed (and so treated) too late. We have initiated a prospective study of the protocol to evaluate further the implications of its adoption. At present, survival after haploidentical bone marrow transplantation in Europe is poorer than that in some American centres, one of the chief differences being age at diagnosis, ${ }^{2}$ and results also vary between European centres. We hope that a greater awareness of the importance of absolute lymphocyte counts among paediatricians will lead to earlier diagnosis and therefore improved survival for infants with SCIDS born in the UK.

We thank the referring paediatricians, records departments, and haematology laboratories of all hospitals from which the children were referred for their assistance in providing data. We thank Dr O B Eden, then consultant in haematology, Royal Hospital for Sick Children, Edinburgh for allowing us to include infants under his care in the series. We also thank $\mathrm{Dr} M$ Reid and Dr P Saunders and the staff of the departments of haematology of Newcastle General Hospital and Royal Victoria Infirmary, Newcastle upon Tyne, for their help in obtaining Infirmary, Newcastle upon Tyne, for their help
data from control children, and for giving advice.

1 Stiehm ER, ed. Immunologic disorders of infants and children. 3rd Ed. Philadelphia: W B Saunders, 1989: 166.

2 Fischer A, Landais P, Freidrich W, et al. European experience of bone-marrow transplantation for sever combined immunodeficiency. Lancet 1990; 336: 850-4

3 Hosking CS, Roberton DM. Epidemiology and treatment of hypogammaglobulinemia. Birth Defects 1983; 19: 223-77.

4 World Health Organisation. Immunodeficiency. Report of a
WHO scientific group. Clin Immunol Immunopathol 1979; 13: 296-359.

5 Fasth A Primary immunodeficiency disorders in Sweden: cases among children 1974-9. F Clin Immunol 1982; 2 86-92.

6 Hayakawa H, Iwata T, Yata J, Kobayashi N. Primary immunodeficiency in Japan: overview of a nationwide survey on primary immunodeficiency syndromes. $7 \mathrm{Clin}$ Immunol 1981; 1: 31-9.

7 Jones JF, Rittenbaugh CK, Spence MA, Hayward A. Severe combined immunodeficiency among the Navajo. I Characterisation of phenotypes, epidemiology, and population genetics. Hum Biol 1991; 63: 669-82.

8 Bortin MM, Rimm AA. Severe combined immunodeficiency disease. Characterization of the disease and results of transplantation. $\mathscr{J} A M A$ 1977; 238: 591-600.

9 Gelfand EW. SCID continues to point the way. $N$ Engl $f$ Med 1990; 322: 1741-3.

10 Gossage DL, Buckley RH. Prevalence of lymphocytopenia in severe combined immunodeficiency. $N$ Engl $f$ Med 1990; 322: 1422-3.

11 Lubin BH. Reference values in infancy and childhood. In: Nathan DG, Oski FA, eds. Hematology of infancy and childhood. Philadelphia: WB Saunders, 1987.

12 Peter HH, Freidrich W, Dopfer R, et al. NK function in severe combined immunodeficiency (SCID): evidence of a common T and NK cell defect in some but not all SCID a common $T$ and $N$ cell defect in some

13 Fontan G, Garcia Rodriguez MC, Carrasco S, et al. Severe combined immunodeficiency with $\mathrm{T}$ lymphocytes retaining functional activity. Clin Immunol Immunopathol 1988 46: 432-41.

14 Hosking CS, Roberton DM. The diagnostic approach to recurrent infections in childhood. Clin Immunol Allergy 1981; $1: 631-9$.

15 Lyall EGH, Eden OB, Dixon $R$, et al. Assessment of clinical scoring system for detection of immunodeficiency in children with recurrent infections. Pediatr Infect Dis $\mathcal{f}$ in children with

16 Patel MS, Hosking CS. Severe combined immunodeficiency - the experience of the Royal Children's Hospital, Melbourne, 1969-1979. Australian Paediatric fournal 1982; 18: 169-76.

17 de Raeve L, Song M, Levy J, Mascart-Lemone F. Cutaneous lesions as a clue to severe combined immunodeficiency. Pediatr Dermatol 1992; 9: 49-51.

18 Mok JYO, Hague RA, Yap PL et al. Vertical transmission of HIV - the Edinburgh experience. Arch Dis Child 1989; 64: $1140-5$. 